\section{PATHWAYS TO NATURE: TOWARDS AN EXPERIENTIAL LANDSCAPE FOR DEMENTIA CARE ENVIRONMENTS}

\author{
Grachia Kusjantoㅁ, Jacqueline McIntosh², Bruno Marques ${ }^{3}$ \\ ${ }^{1}$ Postgraduate student Victoria University of Wellington, ${ }^{2}$ Senior \\ Lecturer Victoria University of Wellington, ${ }^{3}$ Lecturer Victoria \\ University of Wellington, PO Box 600, Wellington, NZ
}

Jacqueline.mcintosh@vuw.ac.nz,Bruno.marques@vuw.ac.nz

\begin{abstract}
Dementia has become one of the most feared of all diseases, with people over 50 fearing it more than cancer. The progressive and distressing nature of the symptoms extend beyond the person with dementia. Secure dementia care facilities are generally disconnected from the community and often confine their residents. The lack of resources to provide stimulation as well as inactive bodies and minds results in agitation and faster progression of the disease. This research explores how to improve the well-being of the person with dementia, their care givers and the community at large. Through design-led research, this paper reports on a multidisciplinary literature review and first-hand observations of patient behaviours. It explores how landscape architecture can help in creating a better life experience for those with dementia who live in a professional care facility. This study argues that improved well-being can be achieved through design sensitive to the phases of dementia. Strategies include encouraging residents with dementia to experience the outdoor environment. Through a socially active, accessible and experiential space that is easy to navigate and interact with, this paper offers means to reconnect and improve the life experience of the person with dementia, their carers' and the greater society.
\end{abstract}

Keywords: Dementia, identity, landscape design, sensorial engagement, autonomy,

\section{Introduction \\ Dementia affects 1 in 20 people over the age of 65 and 1 in 5 over the age of 80 . As of 2015, worldwide there are an estimated 46.8 million people with dementia. A progressive, degenerative brain syndrome, dementia affects memory, thinking, behaviour and emotion. The distressing nature of the symptoms extend beyond the person with dementia affecting the well-being of the family, care givers and community. As the conditions progress, the person with dementia must be placed in a care facility. However, dementia care facilities are generally disconnected from the community and often confine their residents.}

Since 1990s, there have been significant changes to the approach in the design of facilities designed to heal and rehabilitate people, improving their well-being (Marcus and Sachs, 2014). In particular, there has been a growing appreciation for the positive influence of nature in relation with design (Smith, Roehll and Bonell, 2007). Dr Ulrich, a professor of Architecture, researched how views from a window could influence patient's recovery. He found that patients looking out to a garden healed faster than those who looked out to a wall (1984). Similarly, Sternberg found that patients' sudden interest on the external things was the first sign of improved well-being (2009). A University of Michigan study showed that going outside or being immersed in nature could increase memory retention up to twenty percent (Berman et al. 2008). The effect of nature stimulates both the senses and the mind, maintaining or improving mental cognition and performance.

This paper explores how landscape design can be used to improve the well-being of the person with dementia, their care givers and the community at large. It considers the potential for modifications in the landscape: to reduce the stigma of dementia and to improve socialisation; to improve the sense of place for people with dementia, through improvements to wayfinding, and opportunities for improved mobility and therapy; and to improve the sense of self, by enhancing sensory experience and stimulation of memory.

\section{Social Spaces}

With the decline in memory, people with dementia lose connection with others and often become lonely, eroding their mental and physical well-being. The importance of the social environment has been identified by many (Wildevuur, 2013, Ohman, 2007; Hoey, 2007; Feddersen et al, 2014, McLean, 2007). Wildevuur et al found that "engaging in social relations is important for our personal identity, self-esteem and sense of belonging" (2013). Similarly, Ohman found that the patients' desire for quality of life extended to considerations for: access to social contact, meaningful activities and person's identity as well as being valued and respected by others (2007). Exchanging words is one way of communicating and acknowledging the presence of oneself. However, being acknowledged can be more significant for those with severe dementia who have lost their ability to communicate (Hoey, 2007). McLean suggests that "intersubjectivity of a personhood", which is the act of honouring the vulnerability of others, is a connection that can never be lost (2007). The connection of the patients with their carer is an obvious example, however this bond could also be seen from strangers who acknowledge the presence of the patients through visual communication.

\section{Sense-of-Place: Walking, way finding and therapy}

As memory of place is eroded, many people with dementia develop behavioural problems of which wandering is the most troublesome (Lester, Garite and Kohen, 2012). Patients who wander may injure themselves, which causes trouble for the staff. Therefore, many care centres try to prevent patients from wandering, often through restraint in a secured building. Recently new strategies have been explored, designing care facilities as safe walking environments rather than preventing patients from wandering. Medical researchers realised that allowing for autonomy while walking in an outdoor space could relieve stress and allow patients to exercise their body and mind (Cipriani, Lucetti and Nuti, 2014). As many as $92 \%$ of people who walk outdoors have decrease in depression (Mind, 2007). As we walk, we became aware of the changes in our surroundings, we know unconsciously how far off the edge is safe or which side is most comfortable. Our mind unintentionally shapes spaces as we go, which stimulates the brain (O'Rourke, 2013).The experiences and perceptions allow better understanding of our own position in the world (Long, 2002).

While the ability for mapping and navigating deteriorates as the disease worsens, stimulation can slow down the progression. A space without signs and indications causes anxiety to the patients (Feddersen and Ludtke, 2014). Getting lost becomes part of daily life, as unfamiliar settings appear everyday. When designing an outdoor space, there are two opposing strategies to prevent patients from getting lost. The first is to use objects that strike 
their line of vision, such as landmarks, signs or colours. Directed pathways that allow easy navigation are helpful (Sternberg, 2009). The second strategy is to allow patients to walk aimlessly without having to look for cues and signs. Carers have noted that wanderers tend to walk aimlessly and tend to travel along the path of least resistance. According to Debord, in his theory of derive, an individual may drop their objectivity and action and let themselves be drawn by the attractions of the terrain and the encounters they find (1958). A landscape shaped to allow aimless but continuous walking can permit wanderers to walk without the fear of losing their way. Combined these strategies help to stimulate the sense of space and act as a form of meditation and therapy.

\section{Sense-of-Self: Sensory experience and memory}

The body is used every day to experience and learn its surroundings. Sensory experiences articulate the involvement of "being in the world" and strengthen the sense of reality and self (Pallasmaa, 2013). However, as dementia progresses, the patients' senses deteriorate. The experience of touching can become more significant allowing those with dementia to take action and be part of their surroundings. "Touch is bonded to emotions from earliest childhood" (Sternberg, 2009). This can aid memory for those with dementia when short term and recent memories are eroded. Sensory experiences also help maintain a sense of identity. Embodied sensory memories are universal, primal and will last throughout dementia, providing a vehicle for communicating long after verbal abilities are lost (McLean, 2007).

As dementia progresses, daily routines become a challenge. However, patients need enough stimulation to keep their brain active. Outdoor activities can aid with memory stimulation. In a survey in Finland, staff observed that certain plants helped evoke patients' memories (Marcus and Sachs, 2014). Plants also help in orienting spaces, stimulating senses, creating positive emotions and encouraging social interaction between staff and patients (Marcus and Sachs, 2014). Something familiar, or that catches the eye and fosters touch can trigger the brain and memory. Outdoor spaces that allow multisensory experiences are much more meaningful and unforgettable (Day, 2014).

These general fields of inquiry, aimed to improve the wellbeing of those with dementia, their care givers and the wider community, require more detailed consideration given that dementia is a progressive disease. To be successful, a more fine grained approach to design is required following the three main stages of dementia.

\section{Design Principles}

Stage 1, mild to moderate dementia. As long as the symptoms of dementia do not involve wandering or elopement, residents can stay in an unsecured unit, free to leave the building and pursue their own activities. In Stage 1 dementia, the difficulties faced include emotional instability; finding simple tasks more difficult; losing interests in hobbies and daily activities and finding new fears and avoiding new things.

Designing for Stage 1 dementia seeks to encourage residents to act relatively independently. The design focus is on giving freedom within the confines of the grounds, increasing the accessibility into the immediate surrounding area and allowing for meaningful activities, such as exercising, gardening, reading, walking through an aromatic garden and people watching. These activities increase interaction with other residents and with local community residents.

The use of retaining walls, slope, raised beds and elevated platforms can create boundaries and different spaces for various activities. Gardening areas with easy maintenance, hardy and medicinal plants can aid with memory; sheltered areas with trees and shrubs provide for those who wish to spend their time alone; open grassed areas can accommodate group exercises as well as interaction among residents and the public; and aromatic gardens, which induce respiration and relax body and mind. Areas that are typically fenced off can often be designed to open up to decrease stigma and encourage social interaction. Successful design will use both soft-scape and hardscape elements to provide for different uses.

Stage 2: moderate to severe dementia. Hospital units accommodate those who are also suffering physically. In these units, severe dementia patients can often stay unsecured due to their immobility which prevents them from wandering and elopement.

Design for Stage 2 dementia aims to create a garden that both the patients and the public could visit. Most of the patients who use the garden will be in wheelchairs. For safety and security reasons, berms can be added to pathways to prevent patients from falling off the edge of the path or straying. A slight raised elevation can define the path to keep patients on track, without creating barriers for social interaction as the public can step up onto the path easily.

A garden on either side of a pathway can provide different experiences. A variety of plants create different atmospheres which in turn can reflect the different lifestyles of the individual residents. Along a path, patients can also watch or communicate with visitors who use other features in the garden. Residents can enjoy their environment through; looking out the window to experience changes in seasonal flora and fauna, eating outside and observing community members on their way to work; walking in the garden and observing visitors, families, and young children at play; or playing with animals during SPCA visits.

Stage 3-severe dementia: One of the main reasons for securing residents is due to active wandering and attempts at elopement. Often people with dementia get lost and even injured during this process and therefore need to be kept safe inside the building. These people often lose their ability to communicate, to recognise family and loved ones and to care for themselves. The daily difficulties experienced include: the inability to talk, complete disorientation with surroundings, loss of short term memory and the inability to recognise people or even everyday objects.

To address concerns of wandering and escaping, currently care facilities keep areas secure by locking doors, which can only be accessed by staff. However, with a suitable environment, wandering has been considered positive by many researchers (Lester et al, 2012; Hoey, 2007; Marcus and Sachs, 2014). When there are corners or dead-ends, patients tend to stop, not knowing how to proceed. A continuous loop track can lead the patients around even moving in and out of the buildings. A sensory garden adjacent to the outdoor section can utilise plants that stimulate and create a multisensory experience to make the journey pleasant. By being able to walk outside freely, patients' agitation can be reduced and navigational ability, all of which increase their quality of life and sense of wellbeing. Placement of recreational facilities such as jungle gyms and mixcourts adjacent to secure care facilities can attract the public and staff for recreation and relaxation, while allowing residents to interact through observation.

In severe dementia facilities, opportunities for observation and 
touch can be enhanced. Residents can explore a smaller version of the sensory garden, they can interact with people walking past and observe people playing sport and watch people on their way to work, school and shopping. Seating can encourage observation and shelters can be made to resemble bus stops so as to trigger memories and invite people to sit down. Materials and colour are particularly important for people with severe dementia, dark colours can be experienced as voids or holes, patterns can be confusing and glass is often not always understood as a material. Peripheral vision is also often affected so that visual navigation signs are best located on the ground surfaces or below eye level.

\section{Conclusions}

Landscape design can be used to improve the well-being of the person with dementia, their care givers and the community at large. It can help to reduce the stigma of dementia and to create possibilities for improved socialisation. It can improve the sense of place for people with dementia through improvements to wayfinding, and it can enhance opportunities for improved mobility and therapy. Finally, it can improve the sense of self, by enhancing sensory experience and stimulation of memory.

Designing for dementia requires a fine grained approach due to the progressive nature of the disease. Creating social space focuses on giving freedom and allowing for meaningful activities. These activities increase interaction with other residents but also local community members. Designing for a sense of place focusses on orientation and navigation to increase independence and give more opportunity to explore and access other areas outside of the facility. Designing for a sense of self entails familiar activities such as gardening can link to memory and provide a better living experience. Comfort is experienced through familiar sensory experiences such as the familiar sight of children or families; touch, garden smells and sounds that triggers their memory.

Though much research has been published on the medical and social aspects of dementia and a growing literature exists with respect to the theoretical ideas for dementia design, advice on designing the landscape for dementia is still lacking. This study combines findings from the literature and personal observation. Using them as design guidelines can help designers to explore new ways in designing for dementia related environments that give social interaction, autonomy and better life experience for those affected and improves the well-being of care-givers and the general community.

\section{References}

Berman, M.G. Jonides, J and Kaplan,S. 2008 The Cognitive Benefits of Interacting With Nature Psychological Science, December 19: 1207-1212,

Cipriani, G. Lucetti, Nuti 2014 Wandering and Dementia. Psychigeriatrics. pp 135-142.

Day, C. 2014 Places of the Soul: Architecture and environmental design as healing art. Oxon: Routledge.

Debord, G. 1958 Theory of Derive, Internationale Situationniste.

Feddersen, E and Ludtke I. 2014 Lost in Space. Berlin: Birkhauser Verlag.

Hoey, B. A. 2007. Therapeutic uses of place in the intentional space of purposive community.Williams, Allison. Therapeutic Landscapes. Hampshire: Ashgate Publisher Limited. Pp 297- 314.

Lester, P E, Garite A and Kohen I. 2012 Wandering and Elopement in Nursing Home. Annals of Long Term Care.
Long, Richard. 2002 Walking the line. London: Thames \& Hudson.

Marcus, C C. and Sachs N.A. 2014 Therapeutic landscapes: An evidence based approach to designing healing gardens and restorative outdoor spaces. New Jersey: John Wiley \& Sons, Inc.

McLean, A. 2007 The therapeutic landscape of dementia care: Contours of intersubjective spaces for sustaining the person in Williams, A. Therapeutic Landscape. Hampshire: Ashgate Publishing Limited, pp 315 - 332.

Mind. 2007 Ecotherapy: The green agenda for mental health. Mental health. May http://www.mentalhealth.org.nz/assets/ ResourceFinder/ Ecotherapy-The-green-agenda-for-mentalhealth-Executive-summary.pdf. accessed 15 April 2015.

Ohman, A. 2007. Navigating in a changing world: Experiences of everyday life from the perspective of persons with cognitive impairment or dementia. Stockholm: Karolinska Institutet.

O’Rourke, K. 2013 Walking and Mapping : Artists as Cartographers. London: The MIT Press.

Pallasmaa, J. 2013 The Eyes of the Skin: Architecture and the Senses. Hoboken: Wiley.

Smith, J, Roehll G and Bonell L 2007. Design with nature. Healthcare design (2007): 36.

Sternberg, E. M. 2009 Healing Spaces: The science of place and well-being. London: The Belknap Press of Harvard University Press.

Ulrich, R. S. 1984 View through a window may influence recovery from surgery. Science Vol 224 Issue 4647 p 420-421.

Wildevuur, S, van Dijk, D, Hammer-Jakobsen, T. 2013 Connect: Design for an Emphatic Society. Amsterdam: BIS Publishers. 